http://journal.nafo.int

J. Northw. Atl. Fish. Sci., Vol. 19: 127-134

\title{
On Yield and Revenue of Varying Shrimp Stock in the Davis Strait
}

\author{
Steen Christensen \\ Danish Institute of Fisheries Economics Research \\ South Jutland University Centre, Niels Bohrs Vej 9 \\ DK-6700 Esbjerg, Denmark
}

\begin{abstract}
The paper presents a bioeconomic analysis determining the resource rent and optimal effort of the Greenland shrimp (Pandalus borealis) fishery of the Davis Strait. The model simulates the expected yield and revenue applying a constant fishing effort on a varying shrimp stock. Application of selective gears as a measure to restrict over-exploitation is discussed in both biological and economic terms. Variability is introduced into the model by generating the stock size by age randomly from a distribution function developed from random numbers. Applying a lognormal distribution, the coefficients of variance are generated for both revenue and yield about 10 times higher than when a uniform distribution is applied. The optimum resource rent is obtained at an effort level about $50 \%$ lower than the one generating maximum biological yield. At constant effort a mesh size increase from $43 \mathrm{~mm}$ to $55 \mathrm{~mm}$ may reduce catches but increases revenue by $50 \%$.
\end{abstract}

Key words: Bioeconomics, Davis Strait, shrimp, statistical model.

\section{Introduction}

The fishery for shrimp (Pandalus borealis) in the offshore fishing grounds of the Davis Strait in NAFO Subarea 0 and 1 more than 3 naut. miles west of the Greenland archipelago, has been assessed since 1976, first by the International Commission for the Northwest Atlantic Fisheries (ICNAF) and, after 1979, by the Scientific Council of the Northwest Atlantic Fisheries Organization (NAFO). Although much effort has been put into ageing shrimps, ageing uncertainties have so far restrained NAFO from applying analytical assessment models such as virtual population analysis (VPA) (see e.g. Horsted, MS 1990). As a consequence, the annual recommendations have been based on logbook information on catches of the commercial fisheries and a survey series which began only in 1988. Recommended total allowable catches (TACs) are therefore reflections of trends in catch rates and yields of the fishery, rather than dynamic forecasts relating yield and effort.

In 1992 NAFO extended the assessment analysis also to include an index of catch-per-unit effort (CPUE) of large shrimp (>8.5 g) (Carlsson and Lassen, MS 1991) and length frequency data from survey samples (NAFO, 1992). These data indicated a reduction in abundance of large shrimp in the stock and suggested that the 1985 year-class constituted almost the entire catchable stock with the 1989 year-class being the only significant younger year-class. On that basis, NAFO recommended an immediate precautionary $20 \%$ reduction in the shrimp quota and measures to reduce discarding, e.g. increase in mesh size, should be established to secure future recruitment (NAFO, 1992).

However, neither Greenland nor Canada implemented any restrictions on the shrimp fishery in 1992, which surprisingly produced the highest catch ever recorded. Given the success of the 1992 fishery, the continuous stability in the catch rates and in the biomass estimates, and an unexpected appearance of an apparently strong 1986 year-class in the 1992 survey, the Scientific Council of NAFO at its June Meeting in 1993 (NAFO, 1994), recommended that the TAC in both 1993 and 1994 should be kept at 50000 tons.

A thorough description of the Greenland shrimp fishing sector is given by Christensen and Vestergaard (1993). A major part of the fishing fleet is constituted by factory trawlers with processing plants on board. As part of the licence conditions, these factory trawlers are allowed to process 30\% to $90 \%$ of the reported catch on board. Another group of smaller vessels participating in the offshore fishery is not licensed to process on board. These boats are allowed to fish inshore but their entire catch must be landed at landbased factories.

There are three main products of shrimp derived from the catches. At sea, frozen, unpeeled shrimps which can be either raw or cooked are produced. The onshore processing industry produce cooked and peeled shrimps. The sale prices depend on the 
type of product and the size of the shrimp. The commercial fleet operates commonly with 5 size categories (these are count categories, where count is defined as number of shrimp per $\mathrm{kg}$ : 50-70, 7090, 90-120, 120-150 and 150-300.

By means of a static bioeconomic model Christensen and Vestergaard (1993) estimated the resource rent from the shrimp fishery in the Davis Strait in 1991 at DKK 200-600 million, depending on the concept of costs, and demonstrated that it could be increased in the long term by reduction in the effort. As indicated by the survey and catch data, the underlying assumption of constant recruitment in that study was not properly fulfilled. In this context, the present study suggests a dynamic model to simulate the variability in yield and value of the offshore shrimp fishery in the Davis Strait applying constant fishing effort on a varying stock. Also the bioeconomic implications of an increase in mesh size from $43 \mathrm{~mm}$, that has been in force since the start of the offshore fishery, to 55 $\mathrm{mm}$, is analyzed.

The performance statistics are estimated by Monte Carlo simulations as the means of 1000 realizations of the stochastic model. In the simulation, 1991 was chosen as reference year as this was the only year with full information about the economic parameters, i.e. prices per $\mathrm{kg}$ of the different count groups and the costs per fishing day.

\section{The Model}

The objective function applied to calculate the resource rent, $\pi$, of the fishery can be expressed by the following equation:

$$
\pi=\sum_{T} T R\left(p_{1}, H_{l}\right)-T C\left(G_{l}, H_{l}, E\right)
$$

where $\mathrm{TR}=$ total revenue,

$\mathrm{TC}=$ total cost,

$\mathrm{E}=$ total effort,

$\mathrm{p}_{1}=$ average sale price per $\mathrm{kg}$ live weight of count $I$,

$\mathrm{H}_{1}=$ reported catch of count $/$,

$G_{1}=$ gross revenue of reported catch of count $l$.

The harvest function of the bioeconomic model (1) was specified by:

$$
H_{1}(E)=\left(Y_{1}(E)-D_{1}\right)
$$

where $Y_{1}=$ total catch of count $I$, $D_{1}=$ discard of count $/$.

The catch-at-age, $Y_{a}$, and the total catch, $Y$, was calculated by the catch equation:

$$
Y=\sum_{a} R_{a} \times\left(1-\exp \left(-Z_{a}\right)\right) \times \frac{F_{M A X} \times S_{a}}{Z_{a}} w_{a}
$$

where $\mathrm{R}_{\mathrm{a}}=$ recruitment-at-age $\mathrm{a}$,

$F_{\text {MAX }}=$ fishing mortality rate of fully recruited age groups,

$Z_{a}=$ total mortality-at-age $a$,

$\mathrm{w}_{\mathrm{a}}=$ mean weight-at-age $\mathrm{a}$,

$\mathrm{S}_{\mathrm{a}}^{\mathrm{a}}=$ gear selection factor-at-age a. by:

The total mortality-at-age, $Z_{a}$, was calculated

$$
Z_{a}=S_{a} \times F_{M A X}+M
$$

where $\mathrm{M}=$ natural mortality rate.

The age dependent gear selectivity parameter, $S_{\mathrm{a}}$ was introduced by the logistic selection curve:

$$
S_{a}=\frac{1}{1+\exp (T 1-T 2 \times a)}
$$

where

$$
\begin{gathered}
T 1=t_{50} \times \frac{\ln (3)}{t_{75}-t_{50}} \\
T 2=\frac{\ln (3)}{t_{75}-t_{50}}
\end{gathered}
$$

and

$$
\begin{aligned}
& \mathrm{t}_{50}=\mathrm{t}_{0}-\frac{1}{\mathrm{~K}} \times \ln \left(1-\frac{\mathrm{L}_{50}}{\mathrm{~L}_{\infty}}\right) \\
& \mathrm{t}_{75}=\mathrm{t}_{0}-\frac{1}{\mathrm{~K}} \times \ln \left(1-\frac{\mathrm{L}_{75}}{\mathrm{~L}_{\infty}}\right)
\end{aligned}
$$

where a was age and $t_{0}, K$ and $L_{\infty}$ are the von Bertalanffy growth parameters (Hoydal et al., MS 1980).

Variability was introduced into the model by generating the stock size by age, $R_{a}$, randomly from a distribution $F(\mu, \ldots)$ by the TURBO PASCAL 7.0 (Borland Turbo Pascal 7.0 (1992). DOS version. Copyright 1983, 1992 by Borland International) random number generator. In the simulations presented below this distribution was realized as a rectangular distribution.

The mean, $\mu$, of the distribution decreases with age as a function of the total mortality rate:

$$
\mu_{\mathrm{a}}=\mu_{\mathrm{a}-1} \times \exp \left(-\mathrm{Z}_{\mathrm{a}-1}\right)
$$

The arithmetic mean, $\mathrm{AM}_{\mathrm{a}}$, of the distribution was estimated by:

$$
A M_{a}=0.5 \times\left(\alpha_{a}+\beta_{a}\right)
$$

where $\alpha_{a}=$ lower limit of recruitment distribution,

$\beta_{\mathrm{a}}=$ upper limit of recruitment distribution. 
In order to keep $\mathrm{AM}_{\mathrm{a}}$ constant for different ratios between $\alpha$ and $\beta$, these limits were defined as:

$$
\beta_{a}=\mu_{a} \times \sqrt{f}
$$

and

$$
\alpha_{a}=\frac{\mu_{a}}{\sqrt{f}}
$$

where $f=$ fixed ratio between the lower limit, $\alpha$, and the upper limit $\beta$, in the rectangular recruitment distribution.

To study the implications of the uniform distribution of the stock size-by-age, simulations were run assuming that the stock abundance was lognormal distributed. The arithmetic mean AM is then:

$$
A M=\exp \left(\mu+\frac{\sigma^{2}}{2}\right)
$$

These simulations were arranged so that the arithmetic mean remained constant with varying variance:

$$
\mu=\ln (A M)-\frac{\sigma^{2}}{2}
$$

The calculated catches-at-age, $Y_{a}$, are distributed among the different count groups, I, by:

$$
Y_{1}=\sum_{a} Y_{a} \times k_{a, l}
$$

where the distribution matrix, $\mathrm{k}_{\mathrm{a}, \mathrm{l}}$, shown in Table 1, was estimated by algorithms adopted from Sparre and Willmann (MS 1992).

Subsequently, the landings at count group, $\mathrm{H}_{l}$, and the discards at count group, $D_{\mu}$, are estimated by:

$$
D_{1}=Y_{1} \times d_{1}
$$

and

$$
D_{1}=Y_{1} \times d_{1}
$$

where $d_{1}=$ discard ratio of count group $/$.

The total landings and discards are calculated as:

$$
H=\sum_{1} H_{l}
$$

and

$$
D=\sum_{T} D_{1}
$$

respectively, and the total revenue is calculated by:

$$
\mathrm{TR}=\sum_{\mathrm{l}} \mathrm{H}_{1} \times \mathrm{p}_{\mathrm{l}}
$$

Based on information from the accounts of a reference factory trawler, Christensen and Vestergaard (1993) estimated the total cost, TC, of the objective function (1), by:

$$
\mathrm{TR}=\sum_{\mathrm{T}} \mathrm{C}\left(\mathrm{G}_{\mathrm{l}}\right)+\mathrm{C}\left(\mathrm{H}_{\mathrm{l}}\right)+\mathrm{C}(\mathrm{E})
$$

where $c\left(G_{1}\right)=$ costs depending on the value of the reported catch (sales provision and resource tax),

$\mathrm{c}\left(\mathrm{H}_{1}\right)=$ cost depending on the volume of the reported catch (insurance, transport, salt, handling and packaging materials),

$c(E)=$ costs depending on effort (fuel, wages to the crew, and repair and maintenance of gear and vessel).

In all simulations, effort costs were assumed proportional to the fishing mortality rates.

\section{Materials and Methods}

Carlsson et al. (MS 1993) provided estimates of the strength of the individual age-classes in the period 1988-92 indicating that the ratio between the lower and the higher year-class strength is about 8-9 (Table 2). In the present study, variation in recruitment was obtained by applying values of 3 , 9 and 27 as estimates of $f$ in equations (8) and (9).

The average number of recruits at age $3, R_{3}$, determines the average catch level. The best estimate of the long-term average catch, at fixed effort, may be the annual TAC recommended by the Scientific Council of NAFO. Therefore, $\mathbf{R}_{3}$ was tuned to a level generating an average annual landing about 50000 tons, the TAC level in 1991.

Based on samples from the Davis Strait, Savard et al. (MS 1989) provided estimates of mean lengthat-age (Table 1). Carlsson and Kanneworff (MS 1993) found that these estimates are still consistent with estimates based on data from the present stock. In the present study, assuming that growth is following the von Bertalanffy growth equation (Bertalanffy, 1938), the lengths-at-age, $L_{a}$, were estimated by:

$$
\mathrm{L}_{\mathrm{a}}=\mathrm{L}_{\infty}\left(1-\exp \left(-\mathrm{K}\left(\mathrm{a}-\mathrm{t}_{\mathrm{o}}\right)\right)\right.
$$

where $L_{\infty}=$ the infinite length,

$$
\begin{aligned}
& \mathrm{K}=\text { the growth rate, } \\
& \mathrm{t}_{0}=\text { the age at which length is zero. }
\end{aligned}
$$

Regressing the annual increment, calculated from Table 1, against the estimates of length-at-age, the parameter $L_{\infty}$ of the growth equation (19) was 
estimated at $35.65 \mathrm{~mm}$ and $\mathrm{K}$ at 0.154 per year. Subsequently, $t_{0}$ was estimated at -0.7 as described by Gulland (1983).

Weights-at-age, $w_{a}$ in equation (3), were subsequently estimated (Carlsson, Greenland Fisheries Research Institute, Copenhagen, Denmark, pers. comm.) by:

$$
W_{a}=0.000711 \times L_{a}^{2.93}
$$

The size distributions from surveys, Carlsson et al. (MS 1993) provided total mortality estimates between 0.24-1.05 per year (Table 2). Based on initial simulations, a value around 0.70 per year for total mortality, Z, which is close to the 4 year mean of age 6+, was found appropriate and applied in the present study.
In order to calculate the fishing mortality rate, F, of 1991 from the total mortality, Z, assumptions must be made with regard to the level of the natural mortality, M. No information was available in the literature on the level of the natural mortality of shrimp in the Davis Strait. A working group assessment (Anon., MS 1977) suggested 0.2-0.3 per year as an estimate of the Icelandic shrimp stock, whereas the natural mortality rate of shrimp in Skagerrak and Fladen Ground in the North Sea is believed to be higher than 0.5 per year. Rønnow (MS 1992) estimated a value of about 0.6 per year for shrimp in the Disko Bay using data from before 1960. Assuming that predation on the shrimp in the Davis Strait was reduced due to the current low cod abundance and assuming that the diversity of potential predators was low compared to Fladen

TABLE 1. The input parameters for the calculation of catch-at-age distributed among the different count groups.

\begin{tabular}{|c|c|c|c|c|c|c|c|}
\hline \multirow[b]{2}{*}{ Age } & \multirow[b]{2}{*}{$\begin{array}{l}\text { Avg. length } \\
(\mathrm{mm})^{2}\end{array}$} & \multicolumn{6}{|c|}{ Ratio of age group a belonging to count group $l, \mathrm{k}_{\mathrm{a}, l}{ }^{1}$} \\
\hline & & $\begin{array}{l}\text { Count } \\
50-70\end{array}$ & $\begin{array}{l}\text { Count } \\
70-90\end{array}$ & $\begin{array}{c}\text { Count } \\
90-120\end{array}$ & $\begin{array}{c}\text { Count } \\
120-150\end{array}$ & $\begin{array}{c}\text { Count } \\
150-130\end{array}$ & $\begin{array}{l}\text { Count } \\
300+\end{array}$ \\
\hline 1 & 8.4 & & & & & & \\
\hline 2 & 12.3 & & & & & & \\
\hline 3 & 15.7 & - & - & - & - & 0.16 & 0.84 \\
\hline 4 & 18.5 & - & - & - & - & 1.00 & - \\
\hline 5 & 20.6 & - & - & - & 0.12 & 0.88 & - \\
\hline 6 & 22.7 & - & - & 0.15 & 0.85 & - & - \\
\hline 7 & 24.9 & - & - & 1.00 & - & - & - \\
\hline 8 & 26.3 & - & 0.48 & 0.52 & - & - & - \\
\hline 9 & & - & 1.00 & - & - & - & - \\
\hline 10 & & 0.34 & 0.66 & - & - & - & - \\
\hline 11 & & 1.00 & - & - & - & - & - \\
\hline 12 & & 1.00 & - & - & - & - & - \\
\hline Price & $\mathrm{KK} / \mathrm{kg}^{1}$ & 89.2 & 34.69 & 21.19 & 9.86 & 5.43 & - \\
\hline
\end{tabular}

1 Source: Christensen and Vestergaard, 1993.

2 Source: Savard et al., MS 1989.

TABLE 2. Abundance of shrimp (10-6)-at-age and total mortality rates (Z) estimated from Greenland trawl surveys, 1988-92.

\begin{tabular}{rrrrrr}
\hline \hline Age & 1988 & 1989 & 1990 & 1991 & 1992 \\
\hline 2 & 549 & 461 & 852 & 182 & 846 \\
3 & 1122 & 4775 & 1076 & 726 & 2932 \\
4 & 4534 & 16499 & 3227 & 1970 & 3753 \\
5 & 9354 & 7212 & 11967 & 2529 & 6736 \\
6 & 8304 & 3985 & 5289 & 8564 & 10610 \\
$7+$ & 9970 & 6398 & 8146 & 5257 & 6459 \\
\hline Total & 33832 & 39331 & 30556 & 19228 & 31336 \\
\hline$Z(5+)$ & & 0.98 & 0.27 & 0.61 & -0.04 \\
$Z(6+)$ & & 1.05 & 0.24 & 0.94 & 0.76 \\
\hline
\end{tabular}

Source: Carlsson et al., MS 1993. 
Ground and Skagerrak, 0.35 was adopted in the present study as an estimate of $\mathrm{M}$. Accordingly, also the fishing mortality rate of the fully recruited size groups $F_{\text {MAX }}$ was estimated at 0.35 per year.

Christensen and Vestergaard (1993) estimated the total volume of the size discard of 1991 at 13 197 tons, equivalent to a discard rate at $8.1 \%$ of the catch of count $120-150$ and of $69.1 \%$ of the catch count $150+$. These estimates were adopted as estimates of $d$, in equations (13) and (14).

To obtain a discard size distribution close to the one of the commercial fishery in 1991 (Lehmann and Degel, MS 1991; Carlsson and Kanneworff, MS 1992) $19.2 \mathrm{~mm}$ carapace length (CL) was applied as an estimate of the $50 \%$ retention range, $L_{50}$ in equation (5), in the present study. This estimate was reached by initial simulations minimizing the sum of squares of the differences between the sizes of the observed and estimated count groups. However, surveys indicate that $L_{50}$ of the commercial shrimp trawls is about 16-18 $\mathrm{mm}$ (Christensen and Lassen, MS 1990; Lehmann et al., 1993). The discrepancy may be due to differences in fishing behaviour between scientific stratified-random surveys and commercial trawlers, the latter targeting fishing grounds with larger shrimps.

The economic parameters (i.e. prices per kg (in Danish Kroner or DKK) of the different count groups, $p_{1}$ (Table 1), the costs per fishing day, and an estimate of the total effort) are adopted from Christensen and Vestergaard (1993). Based on the principle of opportunity costs, they estimated the total cost of one fishing day of a shrimp trawler to be between DKK 42500 and DKK 80 000, depending on the underlying assumption about the level of opportunity cost for labour and the level of the rates of real interest of capital. In the present study, assuming low opportunity costs for labour and low alternative rate of interest of capital, DKK 50000 was applied as an estimate of costs per fishing day. As the total effort applied in 1991 was estimated at 12215 standard fishing days (Christensen and Vestergaard, 1993), the equivalent total annual cost was estimated at about DKK 600 million.

\section{Results}

Two scenarios are presented. The first scenario analyses the impact of the level of the ratio between the lower and upper limit on stock abundance on the performance of the model, and the second scenario estimates the impact of a mesh size increase. In both scenarios, the average yield of the shrimp population comprising age groups 3 to 12 , is adjusted through the recruitment of 50000 tons annually, applying $43 \mathrm{~mm}$ mesh size and a fishing mortality rate equal to the one of 1991, the reference year. The performance statistics, i.e. average yield, revenue and discard, and related variances ( $C V s)$, calculated as the means of the performance statistics of 1000 realizations of the stochastic model, applying 3, 9 and 27 as values of $f$ and $43 \mathrm{~mm}$ and $55 \mathrm{~mm}$ as mesh sizes, are given in Table 3.

Figures 1 and 2 demonstrate the impact of the three different levels of the recruitment factor, $f$, on yield and revenue, respectively. Figure 1 shows that at a recruitment factor of 3 , the probability to catch 60000 tons or less is $95 \%$ using $43 \mathrm{~mm}$ mesh size. A recruitment factor at 9 or 27 deceases this probability to $85 \%$ and $80 \%$, respectively. The probability of obtaining a revenue of DKK 1.2 billion

TABLE 3. Average yield, discard and revenue at different assumption about mesh size and recruitment factor, f. Results from 1000 simulations.

\begin{tabular}{|c|c|c|c|c|}
\hline \multicolumn{5}{|c|}{ Rectangular distribution: } \\
\hline$f$ & $\begin{array}{l}\text { Mesh size } \\
\quad(\mathrm{mm})\end{array}$ & $\begin{array}{l}\text { Average yield ('000 tons) } \\
\text { and variance }\end{array}$ & $\begin{array}{l}\text { Average revenue } \\
\text { (million DKK) }\end{array}$ & $\begin{array}{c}\text { Discard } \\
\text { ('000 tons) }\end{array}$ \\
\hline 3 & 43 & $\begin{array}{l}49 \\
C V=12.6\end{array}$ & $\begin{array}{c}993 \\
C V=11.1\end{array}$ & 21 \\
\hline 3 & 55 & $\begin{array}{l}48 \\
C V\end{array}$ & $\begin{array}{c}1611 \\
C V=11.9\end{array}$ & 1 \\
\hline 9 & 43 & $C V=19.6$ & $\begin{array}{c}997 \\
C V=17.5\end{array}$ & 21 \\
\hline 27 & 43 & $\begin{array}{l}50 \\
C V=23.3\end{array}$ & $\begin{array}{c}993 \\
C V=20.6\end{array}$ & 21 \\
\hline \multicolumn{5}{|c|}{ Lognormal distribution: } \\
\hline$\sigma=1.8$ & & $\begin{array}{c}49 \\
C V=237\end{array}$ & $\begin{array}{c}975 \\
C V=190\end{array}$ & 21 \\
\hline
\end{tabular}




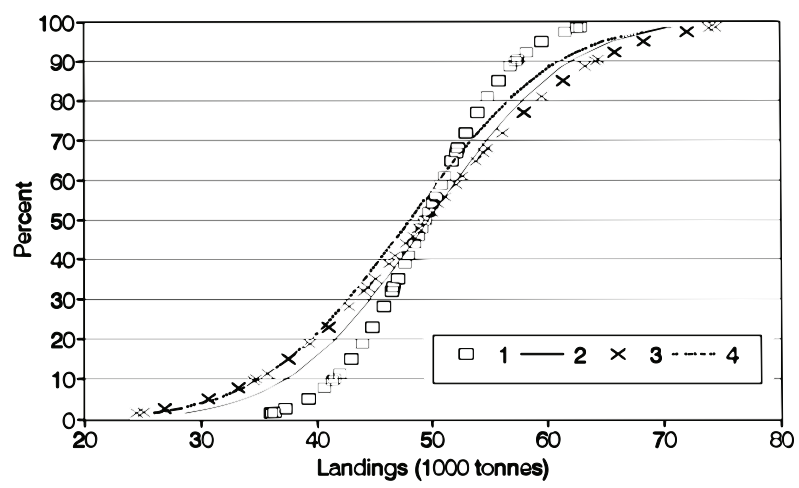

Fig. 1. Probability distribution of yield applying three values of recruitment factor, $f$, and two mesh sizes $(m s)$. Distribution 1 is for $f=3$ and $m s=$ $43 \mathrm{~mm}$; 2 is for $f=9$ and $m s=43 \mathrm{~mm}$; 3 is for $f=$ 27 and $m s=43 \mathrm{~mm} ; 4$ is for $f=9$ and $m s=55$ $\mathrm{mm}$.

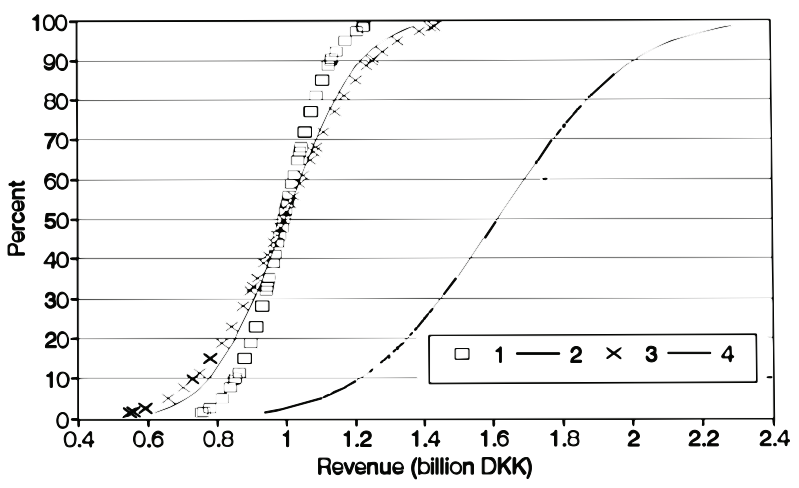

Fig. 2. Probability distribution of revenue applying three values of recruitment factors, $f$, and two mesh sizes $(\mathrm{ms})$. Distribution 1 is for $f=3$ and $m s=$ $43 \mathrm{~mm} ; 2$ is for $\mathrm{f}=9$ and $\mathrm{ms}=43 \mathrm{~mm} ; 3$ is for $\mathrm{f}=$ 27 and $\mathrm{ms}=43 \mathrm{~mm} ; 4$ is for $\mathrm{f}=9$ and $\mathrm{ms}=55$ $\mathrm{mm}$.

by applying 3 as recruitment factor and $43 \mathrm{~mm}$ mesh size is about $97 \%$ (Fig. 2). With 9 and 27 as recruitment factors the probability decreases to $90 \%$ and $85 \%$, respectively.

Increasing the mesh size form $43 \mathrm{~mm}$ to $55 \mathrm{~mm}$, increases the probability only to catch 50000 tons or less from $50 \%$ to about $60 \%$, at a fixed effort level (Fig. 1) but the average revenue increases from DKK 1 billion to about DKK 1.6 billion (Fig. 2).

The average yields at different levels of fishing mortalities applying mesh sizes at $43 \mathrm{~mm}$ and 55 $\mathrm{mm}$, are given in Fig. 3. If the minimum allowable mesh size is increased, the average long-term yield decreases at fixed effort. After a mesh size increase, a gain in long-term yield may be obtained by increasing effort.

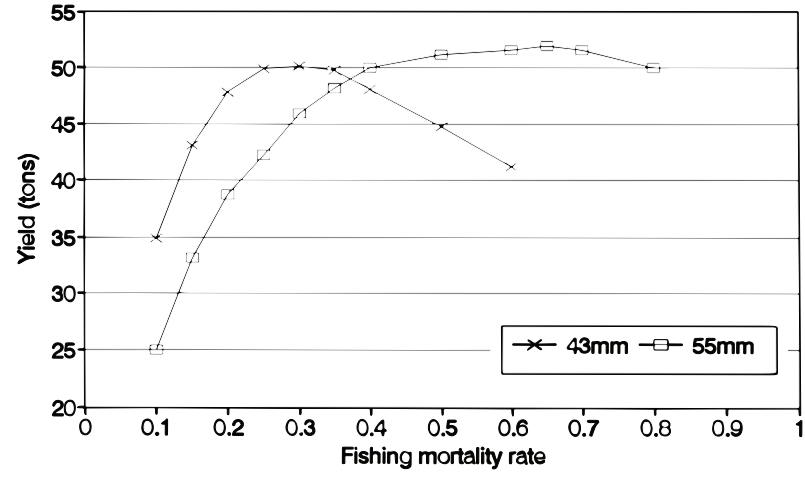

Fig. 3. Average yields at two different mesh sizes as function of fishery mortality rate.

If the objective is to maximize the revenue, the effort should be reduced from the present level, estimated at 12215 days in 1991, to about 7000 days using $43 \mathrm{~mm}$ mesh size (Fig. 4). If the objective is to maximize the resource rent, the effort should be reduced even further to about 5000 fishing days. Figure 4 also shows that the present effort level, about 12000 fishing days, is close to the effort which maximizes the revenue using $55 \mathrm{~mm}$ mesh size. However, in order to maximize the resource rent, the effort should be reduced to about 7 0008000 fishing days.

\section{Discussion}

It is apparent that the predictive value of catch and survey data is still low with regard to the catches of future fisheries and insufficient to meet data requirements of standard analytical fishery models. Assumptions about the future average catch level may, therefore, be hard to quantify.

In the present study, it is assumed that the TAC reflects the best expectations of the productivity of the shrimp stock. Therefore, the average number of recruits is tuned to generate average landings about that level, applying $43 \mathrm{~mm}$ mesh size and the fishing mortality rate estimate of 1991. However, as the actual landings from 1990 to 1992 have exceeded the TAC, apparently without overfishing as the CPUE remained steady, the average longterm yield at constant effort may be at a higher level.

The study emphasizes that the level of CV relies heavily on the choice of recruitment distribution. Table 3 and Fig. 1 and 2 indicate that the CV does not increase proportionally to $f$. This is due to the fact that the upper limit of the uniform distribution quite quickly approaches $2 \times \mathrm{AM}$ and the lower limit 0 . It is therefore not very relevant to make intensive studies for $f>10$. The output from 1000 simulations assuming that the stock abundance is lognormally 


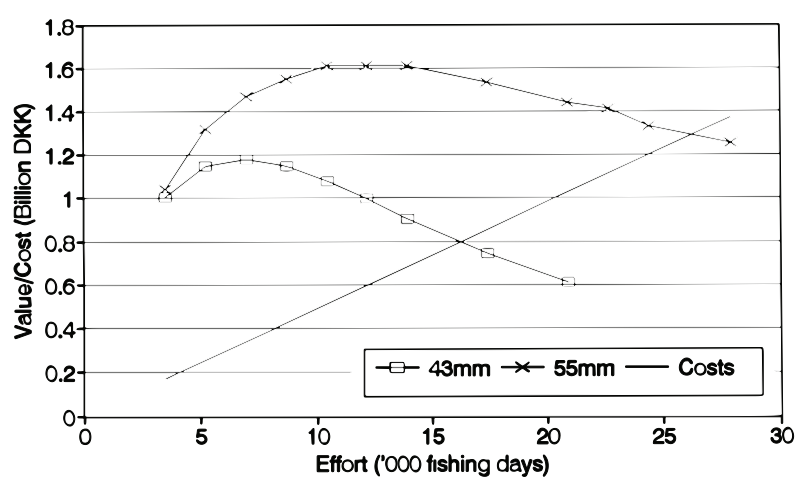

Fig. 4. Average revenue and costs as function of effort applying $43 \mathrm{~mm}$ and $55 \mathrm{~mm}$ mesh size.

distributed with $\sigma=1.8$, is also shown in Table 3, demonstrating how this distribution generates CVs of both revenue and yield about 10 times higher than when a uniform distribution is applied.

The study indicates that a mesh size increase is expected to increase gross revenue substantially from about DKK 1 billion to DKK 1.6 billion without a change in the total yield. Also discards should decrease substantially under such a strategy. The increase in value will only be realized after a new equilibrium is established, i.e. after the increased recruitment have affected all age groups in the population. Such a period will be at least 5 years.

The simulations of a mesh size change are made under the assumption that all selectivity is due to gear selection and that choice of fishing grounds under the historical known fishery with $43 \mathrm{~mm}$ have not changed $L_{50}$ appreciably. Under these assumptions, $L_{50}$ changes from $19.4 \mathrm{~mm} \mathrm{CL}$ to 24.8 $\mathrm{mm} \mathrm{CL}$. Should the apparent selection in the fishery of today be dominated by choice of fishing ground rather than gear selection, then the simulations could be severely invalidated. Further, selection studies by Lehmann et al. (1993) indicate a slightly lower selection factor around 0.4 than the 0.45 applied in this study. Should the 0.4 or even lower be more realistic, the increase in gross revenue would be less.

As fixed prices are applied in all simulations, the economic gain may be overestimated as larger supplies of shrimp may cause a decrease in prices. Also changes in foreign exchange rates may have a sufficient impact on revenue. Further, as constant cost parameters are applied in the model, i.e. expenses to change fishing gear or fishing pattern are not included, the estimated gain in resource rent must cover these expenses also. The economic break-even point is then reached when these expenses equal the excess resource rent.
Ageing shrimps pose uncertainties which have so far restrained NAFO from applying analytical assessment models (Horsted, MS 1990). It has so far only been possible to age shrimp up to age 8 (Table 1). Beyond this, age assumptions must be made with regard to growth, mortality and longevity which are difficult to test. Introducing a plus group (age 9+) would not render any improvements, as this group would contain two count groups of very different value (see Table 1), which would make the initial tuning of the simulated catches to the commercial catches of 1991 difficult.

In the present simulations, the von Bertalanffy growth equation was applied to describe the average growth of the whole shrimp population. By this procedure significant changes in growth rates of the individuals, e.g. due to sex change, may be smoothed out. Taking into consideration that both growth rate and time of sex change of the individuals are influenced by fluctuating hydrographic conditions, it is not believed that application of the von Bertalanffy growth equation has an important impact on the conclusions presented here.

Recruitment patterns in the Davis Strait shrimp population have shown the occurrence of occasional strong year-classes, which begin to contribute to the fishery at a relatively early age and later may result in higher than average catch rates. Average size of shrimp in the catches tend to be smaller when the year-class first appears in significant numbers, but increases over time as they grow and continue to dominate. As catch in the present study is distributed on count groups by algorithms based on the growth rate, the product mix varies during these years due to the year-class effect. This may not reflect reality, however, as the discard ratios applied in the present study is based on the fishery of 1991. A change in size distribution of the shrimp population may, most likely, change the fleet behaviour and highgrading of the catches may occur, violating the underlying assumption about a constant discard ratio.

\section{References}

ANON. MS 1977. Report of the working group on assessment of Pandalus borealis stocks: Conwy 2426 May 1977. ICES C. M. Doc., No. K:10.

BERTALANFFY, L. VON. 1938. A quantitative theory of organic growth (inquires on Growth Laws II). Hum. Biol., 10: 181-213.

CARLSSON, D. M., M. ANDERSON, P. KANNEWORFF, D. G. PARSONS, and H. SIEGSTAD. MS 1993 Assessment of shrimp in Davis Strait (Subareas 0+1). NAFO SCR Doc., No. 81, Serial No. N2266, 19 p.

CARLSSON, D. M., and P. KANNEWORFF. MS 1992. Estimate of shrimp discard from shrimp factory trawlers in Davis Strait and Denmark Strait in 1991. 
NAFO SCR Doc., No. 56, Serial No. N2109, 6 p.

MS 1993. Stratified-random trawl survey for shrimp (Pandalus borealis) in NAFO Subareas $0+1$, 1992. NAFO SCR Doc., No. 70, Serial No. N2254, 9 p.

CARLSSON, C. M., and H. LASSEN. MS 1991. A catchrate index for large shrimp in the Greenland shrimp fishery in NAFO Division 1B. NAFO SCR Doc., No. 57, Serial No. N1941, $14 \mathrm{p}$.

CHRISTENSEN, S., and H. LASSEN. MS 1990. Selection in shrimp trawl. NAFO SCR Doc., No. 56, Serial No. N1777, $3 \mathrm{p}$.

CHRISTENSEN, S., and N. VESTERGAARD. 1993. A bioeconomic analysis of the Greenland shrimp fishery in the Davis Strait. Mar. Resource Economics, 8: 345365.

GULLAND, J. A. 1983. Fish stock assessment: a manual of basic methods. FAO/Wiley series on Food and Agriculture, Vol. 1. John Wiley and Sons, Chichester.

HORSTED, Sv. Aa. MS 1990. Biological advice for and management of some of the major fisheries resources in Greenland waters. NAFO SCR Doc., No. 99, Serial No. N1834, $25 \mathrm{p}$.

HOYDAL, K., C. J. RØRVIK, and P. SPARRE. MS 1980. A method for estimating the effective mesh size and the effect of changes in gear parameters. ICES C. M. Doc., No. G:28.

LEHMANN, K., and H. DEGEL. MS 1991. An estimate of shrimp discard from shrimp factory trawlers in Davis Strait and Denmark Strait in 1991. NAFO SCR Doc., No. 40, Serial No. N1920, 11 p.

LEHMANN, K., J. W. VALDEMARSEN, AND F. RIGET. 1993. Selectivity in shrimp trawl codends tested in a fishery in Greenland. ICES Mar. Sci. Symp., 196: 80-85.

NAFO. 1992. Scientific Council Reports, June 1992 Meeting. NAFO Sci. Coun. Rep., 1992: 25-167.

1994. Scientific Council Reports, June 1993 Meeting. NAFO Sci. Coun. Rep., 1994: 3-148.

RØNNOW, B. MS 1992. Analysis of the catch curves for Pandalus borealis in Disko Bay, West Greenland. NAFO SCR Doc., No. 54, Serial No. N2107, 12 p.

SAVARD, L., D. G. PARSONS, and D. M. CARLSSON. MS 1989. Age and growth of shrimp (Pandalus borealis) in Davis Strait (NAFO SA 0+1). NAFO SCR Doc., No. 94, Serial No. N1694, $14 \mathrm{p}$.

SPARRE, P., and R. WILLMANN. MS 1992. Beam 4, a bioeconomic multi-species, multi-fleet, multi-plant, multiarea extension of the traditional forecast model. ICES C. M. Doc., No. D:2. 